\title{
Empowering Financial Inclusion through Financial Literacy
}

\author{
Sarath Chandran. M.C. \\ Department of Commerce and Research Centre, St. Albert's College, Ernakulam Mahatma Gandhi University, \\ India
}

\begin{abstract}
The term 'financial inclusion' means availability of banking services at an affordable cost to disadvantaged and low-income groups. The banking and financial services include savings, deposits, borrowing, payment and remittance facilities. Financial inclusion mainly focuses on the poor who do not have formal financial institutional support and getting them out of the clutches of local money lenders. As a first step towards financial inclusion policy, Regional Rural Banks were set up. With the directive of Reserve Bank of India (RBI), Banks allow low income groups to open 'no frills accounts'. These accounts either have a low minimum or nil balance with some restriction in transactions. RBI has further relaxed KYC norms and restrictions on mobile banking. NABARD has also contributed significantly by introducing SHG-Bank linkage programme, Kisan Credit Card (KCC) Scheme and has sanctioned Trainers' training programme on financial literacy, farmers' service, village knowledge, mobile credit counselling centres and promotion of farmer education. It also includes providing facilities of micro insurance and micro pension. Financial inclusion is a great step to alleviate poverty in India. But to achieve this, the government should provide a less perspective environment in which banks are free to pursue the innovations necessary to reach low income consumers and still make a profit.
\end{abstract}

Keywords: Financial inclusion, KYC, financial literacy, financial services, $S H G$.

\section{Introduction}

In the simplest terms, financial inclusion means providing access to basic financial services at affordable prices, a pre-requisite for ushering in inclusive growth. Growth needs to be sufficiently inclusive if its benefits have to be shared among all or else the growth process itself shall be jeopardized and derailed. Financial Inclusion has the potential to contribute substantially towards 'inclusive growth'. Access to financial services allows the poor to save money outside the house safely, prevents concentration of economic power with a few individuals and helps in mitigating the risks that the poor face as a result of economic shocks. It is now widely acknowledged that financial exclusion leads to non-accessibility, non-affordability and non-availability of financial products. In other terms, financial inclusion is an explicit strategy for accelerated economic growth and is considered to be critical for achieving inclusive growth in the country.

\subsection{Definition}

"Financial inclusion may be defined as the process of ensuring access to financial services and timely and adequate credit where needed by vulnerable groups such as weaker sections and low income groups at an affordable cost."

Therefore, financial inclusion is the process of ensuring access to appropriate financial products and services needed by vulnerable groups such as weaker sections and low income groups at an affordable cost in a fair and transparent manner by mainstream institutional players. Financial inclusion has become one of the most critical aspects in the context of inclusive growth and development.

\section{Growth And Development}

The Indian Government has a long history of working to expand financial inclusion. Nationalization of the major private sector banks in 1969 was a big step. In 1975 GOI established RRBs with the same aim. It encouraged branch expansion of bank branches especially in rural areas. The RBI guidelines to banks show that $40 \%$ of their net bank credit should be lent to the priority sector. This mainly consists of agriculture, small scale industries, retail trade etc. More than $75 \%$ of our population depends directly or indirectly on agriculture. So $20 \%$ of net bank credit should go to agriculture lending. Recent simplification of KYC norm is another milestone.

The main reason for financial exclusion is the lack of a regular or substantial income. In most of the cases people with low income do not qualify for a loan. The proximity of the financial service is another fact. The loss is not only the transportation cost but also the loss of daily wages for a low income individual. Most of the excluded consumers are not aware of the bank's products, which are beneficial for them. Getting money for their financial requirements from a local money lender is easier than getting a loan from the bank. Most of the 
banks need collateral for their loans. It is very difficult for a low income individual to find collateral for a bank loan. Moreover, banks give more importance to meeting their financial targets. So they focus on larger accounts. It is not profitable for banks to provide small loans and make a profit.

Financial inclusion mainly focuses on the poor who do not have formal financial institutional support and getting them out of the clutches of local money lenders. As a first step towards this, some of our banks have now come forward with general purpose credit cards and artisan credit cards which offer collateral-free small loans.3 The RBI has simplified the KYC (Know your customer) norms for opening a 'No frill' account. This will help the low income individual to open a 'No Frill' account without identity proof and address proof.

In any financial system, there are five basic functions to be performed, they are as follows:

a) Facilitate trading, hedging, diversifying, and pooling of risks;

b) Allocate resources;

c) Monitor managers and exert corporate control;

d) Mobilize savings; and

e) Facilitate exchange of goods and services.

It is important that these aspects are covered as they form an integral part of the inclusive approach as well. Another important aspect of financial inclusion is formation of Self Help Groups (SHGs). SHGs are playing a very important role in the process of financial inclusion. SHGs are usually groups of women who get together and pool money from their savings and lend money among them. Usually they are working with the support of an NGO. The SHG is given loans against the group members' guarantee. Peer pressure within the group helps in improving recoveries. Through SHGs nearly 40 million households are linking with the banks.

Banks are now using new technologies like mobile phones to reach low income consumers. It is possible that the telephone providers themselves will start basic banking services like savings and payments. Indian telecom consumers have few links to financial institutions. So without much difficulty telecom providers can win the battle with banks. Banks should therefore be proactive about transferring this technology into an opportunity.

The widening and deepening of financial system, especially the banking network, links development of real sector through opening of branches in relatively less banked or unbanked areas and transferring of funds from net savers to net borrowers and thereby facilitating capital formation. Further, physical access to growth centres through development of a rural road network unleashes the productive capacity of the people living in rural areas and generates positive externalities. Rural roads, by themselves, can be considered a powerful instrument of financial inclusion. Moreover, analysis of State level data has confirmed that increased banking network and per capita income enhanced savings as well as credit inclusion.

The state has to play an important role in financial markets. The role itself is necessitated due to pervasive market failures which in the current globalised scenario are not a rare occurrence. In developing countries both market and government as institutions have their limitations, but it is necessary to design government policies that are attentive to those limitations.

\section{Financial Literacy}

Although the concept is defined usually at convenience by stakeholders, but its broad contours remain same, that is the ability to take informed decisions, make choices leading to empowerment.

\subsection{Definition}

'the process by which financial consumers/investors improve their understanding of financial products, concepts and risks, and through information, instruction and/or objective advice, develop the skills and confidence to become more aware of financial risks and opportunities, to make informed choices, to know where to go for help, and to take other effective actions to improve their financial well-being'. - RBI

There are good intentions and genuine concerns about vast groups of population still unaware of institutional banking concepts and the know-how to make informed decisions. This makes them vulnerable to exclusion from mainstream socio-economic framework. Financial literacy is an engine that will aid achieving comprehensive financial inclusion and hence financial freedom. Access to financial services [1] allows the poor to save money outside the house safely, prevents concentration of economic power with a few individuals and helps in mitigating the risks that poor face as a result of economic shocks. Hence, providing access to financial services is increasingly becoming an area of concern for the policymakers for the obvious reason that it has far reaching economic and social implications. 


\section{The Future}

The earlier research focused on how finance helps an economy. Now, research shows that financial inclusion is as important. The new avenue for research in finance is - making financial inclusion workable.

\subsection{Why can't financial inclusion happen on its own?}

Financial exclusion: It has been found that financial services are used only by a section of the population. There is demand for these services but it has not been provided. [2] The excluded regions are rural, poor regions and also those living in harsh climatic conditions where it is difficult to provide these financial services. The excluded population then has to rely on informal sector (moneylenders etc.) for availing finance that is usually at exorbitant rates. These leads to a vicious cycle.

a.) High cost: It has also been seen that poor living in urban areas don't utilize the financial services as they find financial services are costly and thus are unaffordable. Hence, even if financial services are available, the high costs discourage the poor from accessing them.

b.) Non-price barriers: Access to formal financial services also requires documents of proof regarding a persons' identity, income etc. The poor people do not have these documents and thus are excluded from these services. They may also subscribe to the services initially but may not use them as actively as others because of high distance between the bank and residence, poor infrastructure etc.

c.) Behavioural aspects: Research in behavioral economics has shown that many people are not comfortable using formal financial services. The reasons are difficulty in understanding language, various documents and conditions that come with financial services etc.

Some of the initiative taken by Reserve Bank of India (RBI) includes:

i.) No-Frill accounts: In November $2005, \mathrm{RBI}$ asked banks to offer no-frills savings account which enables excluded people to open a savings account. Normally, the savings account requires people to maintain a minimum balance and most banks now even offer various facilities with the same. No-frills account requires no (or negligible) balance and is without any other facilities leading to lower costs both for the bank and the individual.

ii.) Usage of Regional language: The Banks were required to provide all the material related to opening accounts, disclosures etc in the regional languages.

iii.) Simple KYC Norms: In order to ensure that persons belonging to low income group both in urban and rural areas do not face difficulty in opening the bank accounts due to the procedural hassles, the KYC procedure for opening accounts has been simplified for those persons who intend to keep balances not exceeding rupees fifty thousand (Rs. 50,000/-) in all their accounts taken together and the total credit in all the accounts taken together is not expected to exceed rupees one lakh (Rs.1,00,000/-) in a year.

iv.) Easier Credit facilities: Banks have been asked to consider introducing General purpose Credit Card (GCC) facility up to Rs. 25,000/- at their rural and semi urban branches. GCC is in the nature of revolving credit entitling the holder to withdraw up to the limit sanctioned. The limit for the purpose can be set Based on assessment of household cash flows; the limits are sanctioned without insistence on security or purpose. The Interest rate on the facility is completely deregulated. A simplified mechanism for one-time settlement of overdue loans up to Rs.25, 000/- has been suggested for adoption.

v.) Other rural intermediaries: Banks were permitted in January 2006, to use other rural organisations like Non- governmental organizations, self-help groups, micro-finance institutions etc for furthering the cause of financial inclusion.

vi.) Using Information Technology: A few Pilot projects have been initiated to test how technology can be used to increase financial inclusion. The important measures such as; [3]

- Smart cards for opening bank accounts with biometric identification;

- Link to mobile or hand held connectivity devices ensure that the transactions are recorded in the bank's books on real time basis.

- $\quad$ Some State Governments are routing social security payments as also payments under the National Rural Employment Guarantee Scheme through such smart cards. The same delivery channel can be used to provide other financial services like low cost remittances and insurance.

- The use of IT also enables banks to handle the enormous increase in the volume of transactions for millions of households for processing, credit scoring, credit record and follow up. 
vii.) Financial Education: RBI has taken number of measures to increase financial literacy in the country. It has set up a multilingual website in 13 languages explaining about banking, money etc. It has started putting up comic strips to explain various difficult subjects like importance of saving, RBI's functions etc.

\section{Conclusion}

Financial inclusion is a great step to alleviate poverty in India. [4] But to achieve this, the government should provide a less perspective environment in which banks are free to pursue the innovations necessary to reach low income consumers and still make a profit. Financial service providers should learn more about the consumers and new business models to reach them. The author of this paper discusses the pertinent issues of financial inclusion comprising of narrower and broader aspect, the importance of the financial literacy and the schemes and policies introduced by the Government with the detailed perspective of the pros and cons and steps taken to improve the reach of financial and banking services at grassroots level.

Financial inclusion is the road that India needs to travel toward becoming a global player. Financial access will attract global market players to our country and that will result in increasing employment and business opportunities. Inclusive growth will act as a source of empowerment and allow people to participate more effectively in the economic and social process.

\section{References}

[1]. Financial Services and the means for its improvement' (2009), Dr. G. Costanzo, Readings in Financial Economics

[2]. Financial Banking and allied services' (2011), Vishwesh Pant, ICER.

[3]. Business line - 06.12.13, financial sector and reforms in India.

[4]. Cognizance - vol. 5. Journal of dept. of commerce. St. Albert's college. 